\title{
Long-term trend of indoor volatile organic compounds (VOC)
}

\author{
S. Matysik ${ }^{1}$, P. Opitz ${ }^{2}$ \& O. Herbarth ${ }^{2}$ \\ ${ }^{1}$ Institute of Clinical Chemistry and Laboratory Medicine, \\ University Hospital Regensburg, Germany \\ ${ }^{2}$ Institute of Environmental Medicine and Hygiene, \\ University of Leipzig, Germany
}

\begin{abstract}
Volatile organic compounds (VOCs) are suspected to be associated with health effects. In a first step, the health relevance could be judged using the sum concentration of a set of specific VOCs. This sum consists of a typical pattern of VOCs which may contribute to health disorders in a different way - for example, substances with an irritative, inflammatory or allergy triggering effect. That's why it is impossible to assess the health impact by means of the VOCsum. Furthermore, several groups of substances (or their percentage) can decrease or increase over time with or without influencing the VOCsum. From this point of view, it is necessary to know these typical patterns and to know whether these patterns have changed over the years.

Within the frame of some epidemiological studies we investigated the indoor VOCs exposure burden during a 15 year period. 2679 measurements were performed and 4225 study participants were involved. The study was focused on homes with families. To avoid possible regional-specific confounder effects, this assessment was conducted for an urban centre in Germany with a sufficiently long and continuous time series (1994-2008). VOCs were determined using passive sampling over 4 weeks. The passive samplers were extracted and analysed with gas chromatography-mass spectrometry. All measurement periods were equally distributed over seasons and years.

The time series of some groups of VOCs show a clear trend. A substantial reduction in the total sum of VOCs (about 60\%) and aromatics (about 80\%) could be demonstrated as well as a decreasing trend of alkanes. No such changes could be observed for cycloalkanes, chlorinated hydrocarbons and terpenes. The
\end{abstract}


resulting pattern of $\mathrm{VOC}$ is quite different comparing the situation 15 years ago with the situation at present.

Possible reasons for the reduction of indoor VOCs exposure are most likely due to the applied regulations/guidelines for the VOCs reduction in indoorrelevant products. One problem is the slight increase in terpene exposure because the chemicals of this group have been found to be associated with specific health effects.

The studies show that future emphasis should be directed not only towards the general reduction of anthropogenically generated VOC outdoor exposures, but also towards the reduction of health-relevant indoor VOCs.

Keywords: indoor exposure, VOC, long-term trend, hygiene, environmental medicine.

\section{Introduction}

Indoor volatile organic compounds (VOCs) may be associated with signs and symptoms of ill health [1-8]. Though the associations of VOCs to ill health have been controversially discussed $[9,10]$ some data show that even small dosages may already account for these observed health effects $[2,4,8]$. For this reason, VOCs have incurred a special importance in the regulation of indoor air quality.

How to assess health relevance of measured VOCs? In a first step the relevance can be judged by means of the sum concentration based on the assumption that specific VOC groups contribute to the VOCsum concentration in a fixed part. Different VOCs of course have different influence on health. Therefore, it is necessary to know whether the parts of VOCs have changed in any way (concentration and/or proportion of its components).

This paper presents an evaluation based on the VOCsum concentration. If VOCs are selectively measured and summed up, the proportion of individual constituents, contributing towards the VOCsum total concentration, could still vary. This is critical for the assessment of indoor environments, in case that the proportion of health relevant chemicals has increased over time.

Long-term trend studies are useful in the assessment of the indoor VOCs burden to get an overview about the time trend of a single VOC which contribute predominantly to VOCsum. This fact is of importance especially for those components which are routinely quantified for local health departments. To reveal contributions of indoor VOCs to health disorders, investigations were directed to assess indoor air exposure by means of measurements of a standard mixture of VOCs. This standard mixture is based on a mixture proposed by Molhave et al. [11] to control the indoor air environment.

Considering these facts, the aim of this study was to find out whether:

- the absolute concentration of different VOC groups; and

- the relative ratio between VOC groups,

have undergone changes over a past 15 year period.

It should be pointed out explicitly that the presented paper only deals with the description of the VOCs exposure and not with resulting health effects. 


\section{Methods}

VOCs were measured as part of several epidemiologic studies [12-15] in the participants' residences. The studies were approved by the ethics committee of the University of Leipzig.

4725 participants were involved in the study and 2679 individual measurements were performed during 15 years (1994 until 2008).

\subsection{Sampling}

All measurements were taken using passive samplers [16]. The advantage is to record a mean load over a sampling period of 28 days. Therefore, this method avoids short time peaks. The passive samplers were deposited for 4 weeks in those rooms of residences in which the family spent most of its time.

Following the design of the epidemiological studies it was ensured that all types of houses or flats and all measurement times are similarly distributed. That means in particular that no week, day or season is overrepresented.

\subsection{Analysis}

The method is described in detail in $[15,17,18]$. Briefly, after extraction of the VOC-coated active charcoal layer of the $3 \mathrm{M}$ passive sampler a quantitative VOC analysis using gas chromatography was performed (Autosystem-Gas Chromatography, Perkin Elmer, Flame ionisation detector (FID)/Electron capture detector (ECD), Mass spectrometry detector (MS)).

In the following assessment and for reason of comparability only those 26 components are included, for which a complete set of data was available (Table 2). These 26 VOC are alkanes (heptane, octane, nonane, decane, undecane, dodecane, tridecane), cycloalkanes (methylcyclopentane, cyclohexane, methylcyclohexane), aromatics (benzene, toluene, ethylbenzene, $\mathrm{m}+\mathrm{p}-$ and o-xylene, styrene, 2-, 3-, 4-ethyltoluene), chlorinated hydrocarbons (chlorbenzene, trichloroethylene, tetrachlorethylene), and terpenes ( $\alpha$ - and $\beta$ pinene, limonene, caren).

\subsection{Statistical analyses}

The statistical analyses were performed using Statistica [19] and Excel [20]. The trend was calculated using the Mann-Kendall-test. This test is a non-parametric test and examines the signs of pair wise differences of the VOC time series.

\section{Results}

\subsection{Concentration trends (absolute)}

The sum concentrations (VOCsum) of all VOCs were calculated and are shown in Figure 1. Figure 2 shows the time trend of the contributing VOC subgroups. 


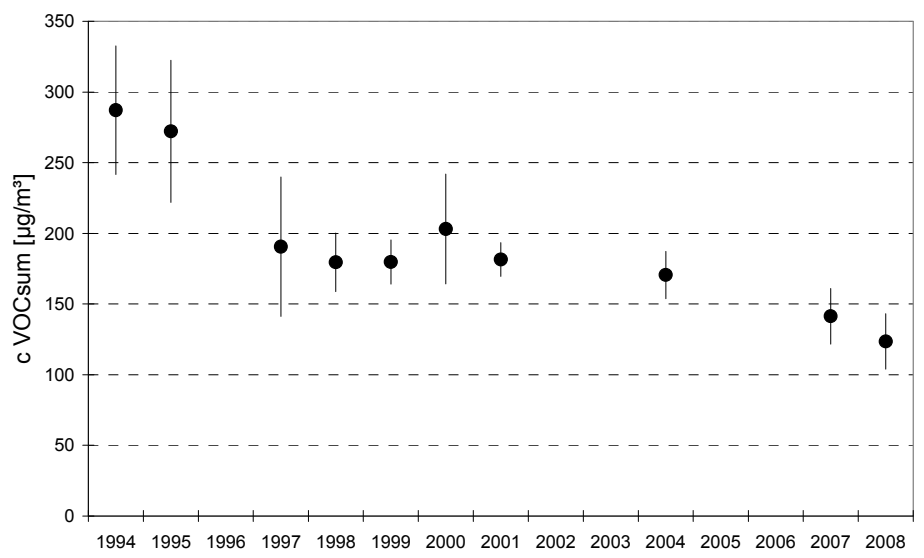

Figure 1: $\quad$ Temporal course of the VOCsum-concentration 1994 to $2008(+/-$ 95\% CI SEM) (SEM - standard error of mean)

The Mann-Kendall trend test used to test the time trend showed a significant decrease for all VOCs (VOCsum) $(p=0.05)$ and for aromatics $(p=0.02)$, as well as a demonstrable reduction for alkanes $(\mathrm{p}=0.08$ trend). With assumption of a linear function alkanes decrease about $-4.1 \mu \mathrm{g} / \mathrm{m}^{3}$, aromatics about $-4.7 \mu \mathrm{g} / \mathrm{m}^{3}$ and terpenes increase about $+0.3 \mu \mathrm{g} / \mathrm{m}^{3}$ per year. The group of cycloalkanes, chlorinated hydrocarbons and terpenes do not indicate any timedependent trend change (Figure 2).

Regarding the individual VOC components the most significant trend was seen for toluene $(p=0.02)$, o-xylene $(p=0.03)$ and 3-ethyltoluene $(p=0.03)$

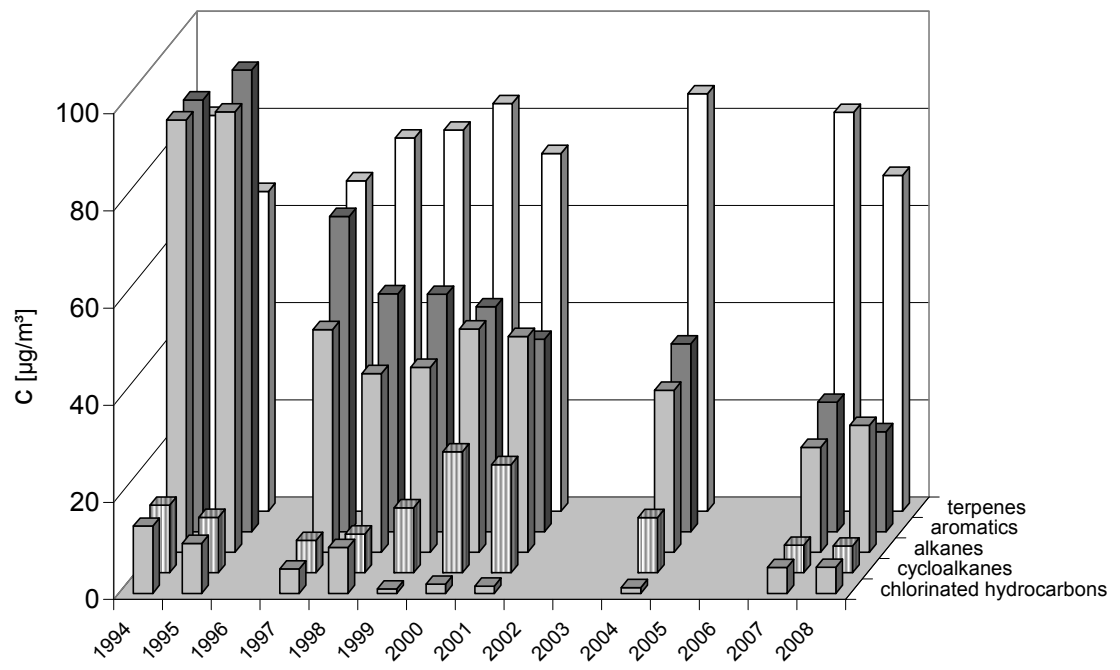

Figure 2: Temporal courses of the means of the VOC-subgroups for 1994-2008. 


\subsection{Trends of the concentrations of the proportional compounds (relative)}

Independent from the general decrease of the VOCsum exposure, the proportion of individual substances to the total burden shows a clear shift. The proportions of the different VOC subgroups are shown in Figure 3. On the one hand, the proportions of alkanes and aromatics decrease; on the other hand, the proportion of terpenes showed an increasing trend (Figure 3).

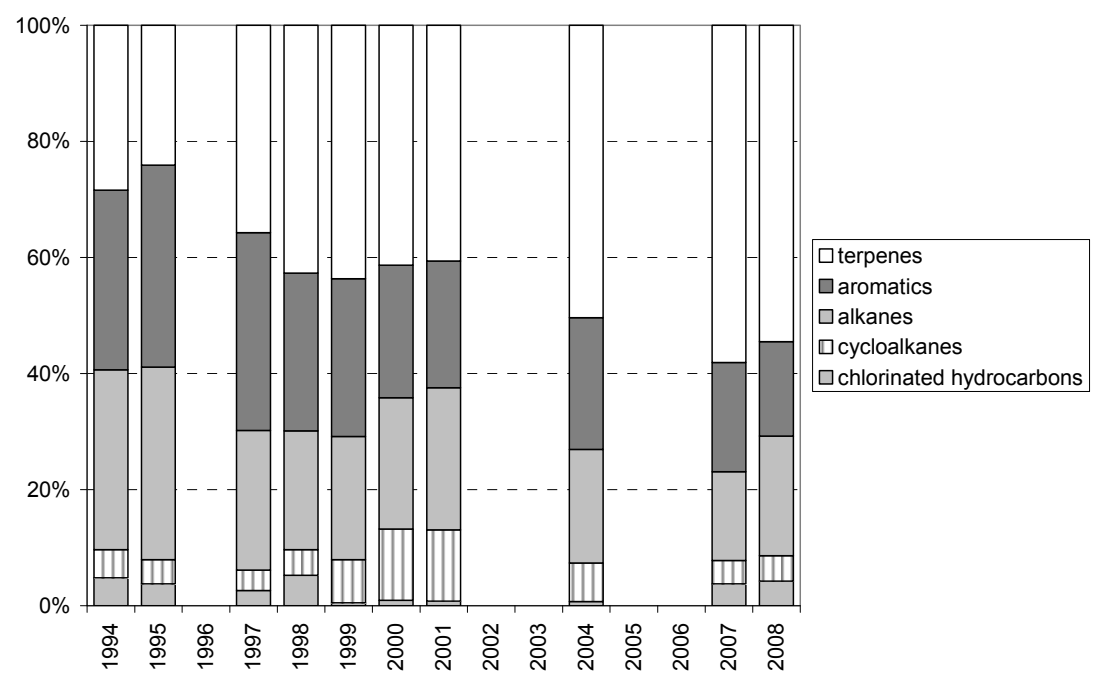

Figure 3: Changes in the proportion [\%] of constituents on the sum VOCburden for the years 1994-2008.

\section{Discussion}

This study could show that over 15 years (1994-2008) clear long-term trends of VOCsum concentrations and of subgroups could be observed. It can be assumed that these changes in the composition of the overall VOC exposure could cause different health effects.

The presented results show a clear reduction in the sum of all VOCs which were under investigation, in particular in alkanes and aromatics, while terpenes increased slightly.

The sum concentration in 2008 was only half of the concentration in 1994.

What are the reasons for these changes? Beginning in the mid-1990s, solvents with a low boiling point generally used in the commercial/industrial production of lacquers and paints, were replaced by glycols and higher alkanes, which do not fall under the definition of solvents (boiling point $<200^{\circ} \mathrm{C}$ ). This is indicated by the decline of "classical" solvents.

- The highest contribution in VOC sum comes from toluene and the higher alkanes. For example: A regulation for toluene was established 
in Germany, in 1996 [21]. We recognized an immediate reduction of $60 \mu \mathrm{g} / \mathrm{m}^{3}$ in $1995 / 96$ down to $23 \mu \mathrm{g} / \mathrm{m}^{3}$ in 1997. The subsequent decrease of $8 \mu \mathrm{g} / \mathrm{m}^{3}$ (from $23 \mu \mathrm{g} / \mathrm{m}^{3}$ to $15 \mu \mathrm{g} / \mathrm{m}^{3}$; the mean between 1999 and 2008), was much less spectacular.

- Another reason could have been prevention. We started information campaigns for young parents about regular use of solvents or solvent containing materials and subsequent health effects in children's health. In the following years VOC-containing products might be handled much more carefully by families. The first of these information events for parents took place in 1996, as a result of our first epidemiologic study [12].

Further studies should also be focused to more attention to indoor VOCproducing microorganisms like mould. In many studies we could show that mould is an increasing indoor problem based on a reduced air exchange rate. This problem not only touches the microbial topics but also the VOC problem, because mould species generate secondary metabolites which are described as MVOC (microbial volatile organic compounds). They include different chemical classes of compounds such as alcohols, alkenes, ketones, ethers, esters, monoand sesquiterpenes [22]. About 200 individual compounds emitted by mould [23, 24] could be detected

In contrast to VOC, several MVOC occur only in very low concentrations, approximately up to $1 \mu \mathrm{g} / \mathrm{m}^{3}$. Due to the increasingly stringent energy-saving policy MVOCs could be a major issue in the future. 3-metyhlfuran, dimethyl disulfide, 1-octen-3-ol, 3-octanone and 3-methyl-1-butanol are recommended as the main indicators for microbial contamination of the interior [25]. Other MVOC are less specific and can also be attributed to building materials, paint, human activities and combustions processes such as smoking and fire [26].

Study limitations:

- The complete time series could only be generated for the considered 26 VOCs $[15,17]$. It cannot be excluded that other than the measured VOCs show a different trend.

- The different sample size per year during the study period may lead to different levels of significance but can be neglected since the sample size in all cases was higher than 100 except 1994 (see Table 1).

Main advantages:

- The study includes a very large number of measurements over a time period of 15 years. No time of year and/or type of apartment/house is over represented due to the applied study design.

- The passive sampling over 4 weeks ensures that activities and peak concentrations generated by short time emissions (e.g., of smoking, life style events, etc.) did not influence the results in a significant way (short-term influence versus long-term average).

It should be addressed in further studies to what extent the results can be transferred to other regions. 


\section{Acknowledgements and grant information}

Some parts of the studies were supported by the SMWK (Ministry of Science and Art of Saxony; grant-no 4-7531.50-03-UFZ/01 and 4-7541.83-UFZ/404c). Parts of the study were supported by the State Ministry of Family and Health of Saxony.

The authors wish to thank the study participants. We are also indebted to our co-workers of the Study Team for the field work.

The final, definitive version of this paper has been published in "Indoor and Built Environment" published online before print September 12, 2012, doi: $10.1177 / 1420326 X 12458298$ by SAGE Publications Ltd., SAGE Publications, Inc., All rights reserved (C2012, International Society of the Built Environment. The content respectively subject matter of the here published version is a short version of the mentioned paper ("Long-term Trend of Indoor volatile organic compounds - a 15-Year Follow-Up Considering Real Living Conditions" Indoor and Built Environment, published online before print September 12, 2012, doi: 10.1177/1420326X12458298) written for these proceedings.

\section{References}

[1] Mendell MJ: Indoor residential chemical emissions as risk factors for respiratory and allergic effects in children: a review: Indoor Air 2007; 17(4): 259-77.

[2] Herbarth O, Fritz GJ, Rehwagen M, Richter M, Roeder S, Schlink U: Association between indoor renovation activities and eczema in early childhood: Int. J. Hyg. Env. Health 2006; 209: 241-247.

[3] Weschler CJ, Wells JR, Poppendieck D, Hubbard H, Pearce TA: Workgroup report: Indoor chemistry and health: Environ Health Perspect 2006; 114(3): 442-446.

[4] Sherriff A, Farrow A, Golding J, Henderson J: Frequent use of chemical household products is associated with persistent wheezing in pre-school age children: Thorax 2005; 60(1): 45-9.

[5] Jaakkola JJ, Parise H, Kislitsin V, Lebedeva NI, Spengler JD: Asthma, wheezing, and allergies in Russian schoolchildren in relation to new surface materials in the home: Am J Public Health 2004; 94(4): 560-2.

[6] Rumchev K, Spickett J, Bulsara M, Phillips M, Stick S: Association of domestic exposure to volatile organic compounds with asthma in young children: Thorax 2004; 59(9): 746-51.

[7] Wolkoff P, Nielsen GD: Organic chemicals in indoor air - their relevance for indoor air quality: Atmospheric Environment 2001; 35: 4404-4417.

[8] Andersson K, Bakke JV, Bjorseth O, Bornehag CG, Clausen G, Hongslo JK, Kjellmann M, Kjaergaard S, Levy F, Molhave L, Skerfving S, Sundell J: TVOC and Health in Non-industrial Indoor Environments: Indoor Air 1997; 7: 78-91. 
[9] Nielsen GD, Larsen ST, Olsen O, Løvik M, Poulsen LK, Glue C, Wolkoff P: Do indoor chemicals promote development of airway allergy?: Indoor Air 2007; 17: 236-255.

[10] Wolkoff P, Clausen PA, Jensen B, Nielsen GD, Wilkins CK: Are we measuring the relevant indoor pollutants?: Indoor Air 1997; 7: 92-106.

[11] Molhave L, Bach B, Pedersen OF: Human reactions to low concentrations of volatile organic compounds: Environ Int 1986; 12: 167-175.

[12] Herbarth O, Fritz GJ, Behler JC, Rehwagen M, Puliafito JL, Richter M, Schlink U, Sernaglia J, Puliafito E, Puliafito C, Schilde M, Wildführ W: Epidemiologic risk analysis of environmentally attributed exposure on air way diseases and allergies in children: Centr. Eur. J. Public Health 1999; 7(2): 72-76.

[13] Diez U, Kroessner T, Rehwagen M, Richter M, Wetzig H, Schulz R, Borte M, Metzner G, Krumbiegel, Herbarth O: Effect of indoor painting and smoking on airway symptoms in atopy risk children in the first year of life - results of the LARS-study: Int. J. Hyg. Environ. Health 2000; 203: 23-28.

[14] Herbarth O: Allergien im Kindesalter / Epidemiology of air pollution associated allergies in children: Bundesgesundheitsbl 2003; 46: 732-738.

[15] 3M Technical Data Bulletin: Organic Vapor Monitor, Sampling and Analysis Guide: 3M Diffusion Monitors 500/3510/3520/3530 Storage and Recovery. Occupational Health and Environmental Safety Division $(\mathrm{OH} \&$ ESD) 1996; 1028: 1-11.

[16] Bates M, Gonzalez-Flesca N, Cocheo V, Sokhi R: Ambient volatile organic compounds monitoring by diffusive sampling. Compatibility of high uptake rate samplers with thermal desorption: Analyst 1997; 122: 1481-1484.

[17] Schlink U, Rehwagen M, Damm M, Richter M, Borte M, Herbarth O: Seasonal cycle of indoor-VOCs: comparison of apartments and cities: Atmospheric Environment 2004; 38: 1181-1190.

[18] Herbarth O, Matysik S: Decreasing concentrations of volatile organic compound (VOC) emitted following home renovations: Indoor Air 2010; 20: 141-146.

[19] StatSoft Inc.: STATISTICA für Windows [Software-System für Datenanalyse] Version 7.1., 2005. www.statsoft.com (accessed July 24, 2012).

[20] Microsoft Excel 2003: 1985-2003 Microsoft Cooperation.

[21] Ad-hoc-AG: Ad-hoc-Arbeitsgruppe der Innenraumlufthygiene-Kommission des Umweltbundesamtes und der Obersten Landesgesundheitsbehörden: Beurteilung von Innenraumluftkontaminationen mittels Referenz- und Richtwerten. Evaluation of indoor air contaminants by means of reference and guideline values. Bundesgesundheitsbl. 2007; 50: 990-1005. DOI 10.1007/s00103-007-0290-y.

[22] Matysik S, Herbarth O, Mueller A: Determination of microbial organic compounds (MVOCs) by passive sampling onto charcoal sorbents: Chemosphere 2009; 76: 114-119. 
[23] Fiedler K, Schütz E, Geh E: Detection of microbial volatile organic compounds (MVOCs) produced by moulds on various materials: Int. J. Hyg. Env. Health 2001; 204: 111-121.

[24] Korpi A, Jarnberg J: Microbial volatile organic compounds: Crit. Rev. Toxicol. 2009; 39: 139-193.

[25] Umweltbundesamt Innenraumlufthygienekommission: Leitfaden zur Vorbeugung, Untersuchung, Bewertung und Sanierung von Schimmelpilzwachstum in Innenräumen: Umweltbundesamt Berlin 2002.

[26] Schleibinger H, Brattig C, Mangler M, Samwer H, Laußmann D, Eis D, Braun P, Marchl D, Nickelmann A, Rueden H: Microbial volatile organic compounds (MVOC) as indicators for fungal damage: Proceedings Indoor Air 2002; 4: 707-712. 